\title{
Who Benefits from Removing User Fees for Health Care? Evidence from a Randomised Experiment in Ghana
}

\author{
Timothy Powell-Jackson*
}

London School of Hygiene and Tropical Medicine; University of Oxford

\author{
Kara Hanson \\ London School of Hygiene and Tropical Medicine \\ Christopher J M Whitty \\ London School of Hygiene \& Tropical Medicine
}

Evelyn K Ansah

Research and Development Division, Ghana Health Service

First Version: $15^{\text {th }}$ February 2012

The extent to which removing user fees for health care in developing countries improves population health rests, in part, on how behavioural responses vary across individuals with different health needs. Using data from a randomised experiment of free care in Ghana and a measure of baseline health that is both objective and broad-based, we examined differential effects for initially ill and healthy children. We find that free care improved health seeking behaviour, lowered out-of-pocket spending and reduced anaemia amongst children who were ill at baseline but had no effect on initially healthy children. Whilst there was no health effect on the intervention population taken overall, the evidence suggests that removing user fees may have enabled individuals with the greatest health need to take up primary health care, thereby improving their health. There was no indication that free care encouraged frivolous use of services.

\footnotetext{
*Corresponding author: Timothy Powell-Jackson, London School of Hygiene and Tropical Medicine, 15-17 Tavistock Place, London, WC1H 9SH. Email: Timothy.PowellJackson@1shtm.ac.uk.

Ethical approval for this study was obtained from the ethical review board of the Ghana Health Service and the London School of Hygiene and Tropical Medicine. We thank the Gates Foundation for financial support. The usual disclaimer applies.
} 


\section{Introduction}

The debate over whether governments in the developing world should charge user fees for health care has received considerable attention for several decades. In policy circles and in the academic literature the issue has ignited passions on both sides of the argument. When government health budgets were shrinking in the late 1980s, user fees were proposed as a means to raise much needed revenue and to discourage unnecessary use of health services. Recent years have witnessed a hardening against this position and a reversal of policy in a growing number of countries in Africa (Commission for Africa, 2005; Gilson and McIntyre, 2005). ${ }^{2}$ The emerging consensus is that "not only do [user fees] deter people from using health services and cause financial stress, they also cause inefficiency and inequity in the way resources are used" (World Health Organization, 2010). Alternatives to user fees - that provide financial protection through tax financing or subsidised health insurance - are regarded as a central pillar in the strategy to improve access to health services.

Despite the contentious nature of the debate and the extent of the literature, it is striking how little rigorous evidence there is on the impact of removing direct payments for health care or introducing health insurance. A recent systematic literature review on user fees, for example, identified over two hundred papers of potential relevance, reduced to just 16 when standard inclusion criteria were applied (Lagarde and Palmer, 2008). The authors noted that "only one study was found to be of good quality [and] even studies that have been highly influential and often quoted failed the quality appraisal." Another notable gap is evidence of the impact of fee removal on health outcomes, as compared to health seeking behaviour.

This paper examines the effect of removing user fees for health care on children using data from a study in southern Ghana. Our empirical investigation complements an earlier paper that presented the initial results of the study. It found free care increased utilisation of formal primary care but did not lead to health improvements in the population under study as a whole (Ansah et al., 2009). By exploring heterogeneity in the effect of free health care, this paper provides a more nuanced understanding of who benefits and why from the removal of user fees, concentrating on the effects on health. On the basis that the impact of free care on health status in the general population is likely to be small and thus difficult to detect (e.g. Newhouse and and the Insurance Experiment Group, 1993), we give particular attention to a subgroup of the population who

\footnotetext{
${ }^{2}$ Yates (2009) identifies 13 African countries that have removed user fees in the past few decades. We know of several countries that were not on this list or have since introduced free health care.
} 
were ill at baseline. We estimate differential effects of free care for children who were initially ill and healthy on a comprehensive set of outcomes that include health care utilisation, out-of-pocket health care spending, and anaemia status.

The removal of user fees can be characterised as a form of health insurance that is anticipated to improve health status through increases in the quantity and quality of health care. The extent to which free health care improves population health rests, in part, on how behavioural responses vary across individuals with different health needs. To illustrate, suppose free care increases health care use of individuals who are healthy. Since the marginal benefit of health care for these individuals is small, free care will have little or no health impact. Indeed, the prospect that removing user fees stimulates only frivolous use has been one of the central arguments voiced against the policy because it suggests a channel through which free care will fail to improve health (Akin et al., 1987). ${ }^{3}$

It is not obvious, a priori, that heterogeneity in the behavioural response to free care will reflect need. The price and income effects of subsidised health care should increase utilisation but theory provides little guidance on variation in the responsiveness of different population groups. Some have argued that the sick will be less responsive to insurance coverage than the healthy because their use of services is less discretionary (Manning et al., 1987), but in a developing country context there is little evidence in support of this view. A substantial proportion of children, in particular the poorest, fail to have access to life-saving health interventions (Jones et al., 2003). Moreover, financial barriers in developing countries are considerable: out-of-pocket spending on health care represents a considerable share of household income (van Doorslaer et al., 2007) and formal credit markets function poorly (Morduch, 1995; Pitt and Khandker, 1998). Predictions as to the effect of free care are further obscured by the possibility that lower prices for curative care discourage investment in preventive and healthy lifestyle behaviours, leading to worse health outcomes (Phelps, 1978).

We shed light on these issues using experimental data from Ghana. In 2005, when user fees were the default policy in the public sector, households in one district

\footnotetext{
${ }^{3}$ Economists have long emphasised the problem of ex post moral hazard in the standard model of health insurance, regarding any increase in demand for health care under insurance as a source of inefficiency (Pauly, 1968). Because insured individuals face only a fraction of the full cost of medical care, they have inefficient incentives to consume a larger than optimal quantity of services (Arrow, 1963; Pauly, 1968). The welfare loss due to moral hazard, however, is likely to be overstated for at least three reasons (Newhouse, 2002). First, there are gains from avoiding the risk of financial loss (Gertler and Gruber, 2002; Zeckhauser, 1970). Second, there may be positive externalities associated with health care, particularly in the case of preventive services, such that health care use absent health insurance is inefficiently low (Culyer and Simpson, 1980). Third, health insurance allows individuals to access care that they would otherwise not have been able to afford (Nyman, 1999). This is particularly true when health care spending is large relative to income (Pauly, 1983).
} 
were randomly assigned either to an existing prepayment health insurance scheme for which the study paid for enrolment, or a control group. Our analysis exploits several unusual features of the data and the study setting. First, we have baseline data on health status that provides an objective basis with which to determine need. Anaemia is a multi-factorial, broad-based measure of child health status, particularly appropriate in a country where malaria is the leading cause of morbidity and mortality amongst children under five years of age. It provides a suitable candidate to distinguish between children who were ill and those who were healthy prior to the removal of user fees. Second, the study collected extensive data on malaria-related preventive behaviours, providing the opportunity to test for ex-ante moral hazard. A third advantage is the prior introduction in the study site of an artemisinin-combination therapy (ACT), an antimalarial drug that was shown in the course of the study to be effective and widely used by providers. This means that we can be confident that drug quality was adequate to generate malaria-related health benefits.

We find that removing direct payments for health care in the public sector increased the use of primary care clinics by 20 percent and lowered out-of-pocket spending on health care by 37 percent for families of children with anaemia at baseline. The increase in utilisation was the result of a shift from informal providers to formal providers rather than an increase in the total quantity of services. By contrast, free care had no effect on the care seeking behaviour or health spending of children with no anaemia at baseline. Consistent with this pattern of results, free care reduced anaemia by 14 percent among the group of children who were ill at baseline, producing health benefits at all quantiles of the initial haemoglobin concentration in this group. We find no health gains for initially healthy children or for the population under study overall.

It is impossible to be certain whether these results will generalise to other contexts, particularly given the lack of comparable studies exploring the role of health need in influencing the impact of health financing schemes. However, in this specific setting, the pattern of gains across groups provide encouraging signs that the removal of user fees enabled individuals with the greatest health need to take up services without promoting frivolous use of services amongst those with no capacity to benefit. Though we find benefits of removing user fees, an important caveat is that its cost-effectiveness as a policy remains unclear.

Our paper contributes to several strands of the literature. First, health economists have long been interested in the impact of health insurance and other forms of financial protection on health-related outcomes. Despite the extensive literature, credible evidence remains limited in developing countries. With the exception of two randomised experiments in Mexico (King et al., 2009) and Nicaragua 
(Thornton et al., 2010), few studies have isolated the causal effect of insurance or abolishing user fees from other confounding factors. Second, most evaluations, experimental or otherwise, are confined to measuring utilisation and out-of-pocket health care spending as an outcome of interest. There is remarkably little empirical research in developing countries on the health benefits of removing direct payments for health care or health insurance. A key contribution of this paper is to study a range of outcomes, thereby providing a comprehensive assessment of the benefits (health and consumption smoothing) and costs (increased health care utilisation) of removing user fees.

In one important respect, the closest antecedent to our paper is a study of the impact of Medicare on mortality (Card et al., 2009). Recognising that few studies of health insurance have been able to show health benefits, they focus on a group of severely ill patients and find that the discontinuity in Medicare as the primary insurer at age 65 corresponds with a fall in mortality. In a similar vein, we focus on children who were ill with anaemia before the removal of user fees and find economically significant benefits for this group. We go one step further than Card et al (2009) to show that not only were there significant differences in impacts for ill and healthy children, there were few, if any, gains for the latter group.

Second, we connect to a closely related but distinct literature on the role of price in influencing the uptake of health care. Field experiments - on bednets (Cohen and Dupas, 2010), home water purification (Ashraf et al., 2010), deworming drugs (Kremer and Miguel, 2007) and HIV testing (Thornton, 2008) - have found that price is an important determinant of use in developing countries. ${ }^{4}$ These papers focus on health products or diagnostic tests, whereas our study is concerned with a system-wide health financing reform. The removal of user fees as an intervention introduces additional complexities - such as quality of care, supply-side incentives, and the timing of care seeking - that require explicit recognition and discussion in our study.

The paper is structured as follows. Section II provides an overview of the free care study in southern Ghana, including its experimental design. Section III describes the data and section IV the empirical methods. Section V presents the main findings of the analysis. Section VI considers the potential channels for the effect of free care and discusses the implications of the findings.

\footnotetext{
${ }^{4}$ More precisely, two of these studies sought to disentangle the effect of price on purchase and use of health products using a two-stage pricing strategy (Ashraf et al., 2010; Cohen and Dupas, 2010).
} 


\section{Background}

\section{II.A Health Financing Policy in Ghana}

After independence in 1957, the new socialist government in Ghana moved to a tax-based financing system, instituting free medical services in public sector facilities. In the context of Ghana's weak economy at the time, this system was perceived to lead to gradually worsening quality of care with widespread shortages of essential medicines, equipment and supplies. In 1985, the then military government re-introduced user fees to recover at least 15 percent of recurrent expenditure for quality improvements, as part of an IMF and World Bank Recovery Programme (Agyepong and Adjei, 2008). Before long, these reforms had earned the name "cash and carry." Studies suggested that there was a significant drop in health service utilisation and increased inequality, particularly in the rural areas (Asenso-Okyere and Dzator, 1997; Creese, 1991; Waddington and Enyimayew, 1989; Waddington and Enyimayew, 1990).

During this time, other strategies for financing health care were pursued. One such scheme was the Nkoranza hospital based health insurance scheme, initiated by the St. Theresa's Catholic Mission Hospital in 1992. Several other community health insurance schemes were set up including the district-wide scheme on which this study is based, incidentally the first in the country. Subsequently, similar schemes known then as Mutual Health Organizations (MHOs) began springing up with facilitation and support from international donors. During this period, two attempts were made by the Government of Ghana to set up a social health insurance scheme, both of which failed. By 2003, there were over 250 community insurance schemes all over the country (Atim, 2010).

In 2001 the newly elected democratic government re-initiated the process of establishing a National Health Insurance Scheme. The bill - the National Health Insurance Act 650 - was passed into law in 2003. Financing of the scheme is by individual premium payments, a 2.5 percent National Health Insurance levy on specified goods and services, and a 2.5 percent formal sector worker contribution to the Social Security and National Insurance Trust, automatically transferred to the National Health Insurance Fund every month. The scheme comprises districtwide MHOs in every district, into which both formal and the non formal sector workers enrol (Agyepong and Adjei, 2008).

\section{II.B Free Health Care Experiment}

We undertook a randomised trial of removing user fees for health care in Dangme West, a poor rural district in Southern Ghana with an estimated population of 115,000 in 2004, around the time of the study. The district had ten primary health 
facilities, but with no district hospital, inhabitants had to choose from five hospitals in neighbouring districts for referral care. Malaria was the leading cause of morbidity and mortality in children under five in the study district.

The study provided free health care to households randomly assigned to the intervention group by paying for them to enrol into an existing prepayment health insurance scheme in May 2004. Households in the control group continued to pay a fee-for-service at public health facilities in accordance with the national policy at the time. Households who had enrolled into the prepayment scheme prior to the start of the study were enlisted on a voluntary basis as a third observational trial arm.

The community prepayment insurance scheme began in 2000, covering the costs of primary care, including diagnostics and drugs with no limit, and a limited set of services provided at the secondary level referral hospital. ${ }^{5}$ It covered the costs of health services in the public sector, allowing members to choose from any of the primary health facilities in the district and a collaborating referral hospital of their choice when referred. To limit adverse selection enrolment had been carried out on a voluntary basis at the household rather than the individual level.

For individuals covered by insurance, health providers were reimbursed by the scheme on a fee-for-service basis. It is important to emphasise that the price of curative care for those assigned to the free care group was not zero. They still continued to face other costs of health seeking, such as transport. Data from the study show that such costs are nontrivial, accounting for 22 percent of total outof-pocket health spending at baseline.

The prepayment insurance scheme was introduced as a response to the problem of high out-of-pocket health care expenditures and the inability of families in the district to afford these payments. Data from the study confirm these earlier observations. At baseline, 17 percent of families who sought care in the past four weeks were not able meet the cost with available savings suggesting potential credit constraints. ${ }^{6}$ Of those households that had an ill child but did not go to a health facility, 38 percent reported the primary reason as "too expensive or could not afford it".

The study was announced to the public only when the enrolment window for the year was closed, such that all households that were going to self-select into

\footnotetext{
${ }^{5}$ The district-wide prepayment scheme studied in this paper was converted into the district-wide MHO for Dangme West District after the study was over in 2006.

${ }^{6}$ This underestimates the extent of the problem because there are likely to be households which did not seek care due to credit constraints and the unaffordability of care.
} 
insurance had already done so. Treatment and control thus comprised households that chose not to self-enrol into the insurance scheme. No household was able to change their allocated group at any point during the one year study period because the enrolment process occurred only once a year. The study assisted households with the administrative process of enrolment, informing members of their benefits and ensuring picture identification cards were issued, resulting in full compliance with treatment assignment.

Households with at least one child aged 6 to 59 months and not already enrolled in the prepayment health insurance scheme were eligible to participate in the study. The sample frame consisted of approximately 8,700 households with children under five years of age living in the study area. Households were selected at random using a computer random number generator and then visited in person. A household was excluded if it had no child under six years of age, did not provide parental consent, was due to migrate from the study area in the next two years, or had previously enrolled into the prepayment scheme. Previous enrolees were invited to participate as an observational third arm.

Households were randomised using a stratified procedure in which they were divided into three strata based on distance of residence from the nearest health facility: less than $5 \mathrm{~km}$; 5 to $10 \mathrm{~km}$; greater than $10 \mathrm{~km}$. A public lottery that involved pulling out "yes" and "no" pieces of paper from a rotating barrel was used to assign households. For ethical reasons, the study paid for households assigned to the control group and those in the observational arm to be enrolled into the prepayment scheme the year following the study.

\section{Data}

\section{III.A Measurement of Outcomes}

The primary health outcome is anaemia, as measured by the proportion of children with haemoglobin concentration less than $10 \mathrm{~g} / \mathrm{dl}$. This is based on criteria developed by the World Health Organisation (DeMaeyer, 1989) and is the same definition used by Ghana's Demographic and Health Survey (Ghana Statistical Service et al., 2009). Anaemia is a good marker of overall health - it is a commonly used objective outcome of community interventions on malaria morbidity and its causes include malaria, inadequate dietary intake of iron and intestinal worm infection, all of which are entirely treatable. We also use the absolute level of haemoglobin concentration as an alternative measure of health. Haemoglobin concentration was measured just before and one year after the introduction of the free care intervention during a household survey that took 
finger-prick blood samples from children aged between 6 and 59 months. Other measures of health status include malaria parasitaemia, and anthropometic measurements such as weight and height. Laboratory methods are described in more detail elsewhere (Ansah et al., 2009).

Data on health care seeking behaviour was collected using pictorial diaries that were supplied to households and collected by trained fieldworkers on a monthly basis during a six month follow-up period so as to limit problems of recall. These diaries recorded the type of illness the child suffered from during the period as well as the type of health provider visited, with the possible options including primary health clinic, hospital, private pharmacy, and traditional healer. We refer to the first two as formal health care providers and the remaining two choices as informal providers. The pictorial diary data are used to calculate utilisation at the extensive margin (ie. any visit) and visits per person per year. During the baseline and endline household surveys, we also collected data on out-of-pocket spending on health care, using a recall period of four weeks. Expenditure data relate to the costs of medical care and other costs such as those associated with transport to and from the health care provider. Finally, additional data on malaria-related preventive behaviours (eg. use of insecticide treated bednets) and family characteristics were collected through the household survey, conducted at both baseline and endline.

\section{III.B Capacity to Benefit}

The analysis presented in this paper is largely devoted to exploring heterogeneity in the effect of providing free health care with respect to need. The concept of need is not easy to define. It is value-laden and difficult to operationalise, and further complicated when the discussion is framed in terms of resource allocation (Culyer, 1995). For the purposes of our study, we simply wish to make the conceptual distinction between any need and no need. We therefore frame need in terms of capacity to benefit which allows us to ignore ill health that is not amenable to medical intervention.

Consistent with the objective of most health care systems, we use the term benefit to refer to health gain. To identify potential benefits (health gains), need should be measured objectively. Implicitly, this means we are not concerned with the idea of felt need, although we fully recognise that an individual's own perception of ill health is likely to be a strong motivating factor to seek health care.

We operationalise this concept of need by using baseline data on children's anaemia status. Specifically, anaemia is used to identify ill and healthy children prior to randomisation and the removal of user fees. Of course, no one indicator of health status can be considered a perfect measure of capacity to benefit. However, 
for children in the study who live in an area where malaria is a major contributor to morbidity and mortality and entirely curable with locally available technology, we believe that anaemia is a salient measure with which to generate a dichotomous indicator of capacity to benefit.

\section{III.C Sample Definition and Descriptive Statistics}

Of the 2,332 households (with 2,757 children of eligible age) that were randomly selected from the district database to participate in the study, no household refused consent. ${ }^{7}$ Within this total, 138 households with 165 children had already enrolled voluntarily into the prepayment health insurance scheme by the time the registration window had closed. They were excluded from the main study but retained as an observational arm. The remaining 2,194 households with 2,592 children were randomly assigned to treatment and control groups.

At the baseline household survey in May 2004 a total of 2,151 households with 2,524 children were found and interviewed (1,227 children in the intervention arm and 1,297 in the control arm). In the final household survey, carried out at the end of the malaria transmission season between December 2004 and February 2005, 969 households with 1,124 children in the intervention arm (attrition of 8 percent) and 1,012 households with 1,197 children in the control arm (attrition of 7 percent) were successfully follow-up. The characteristics of households lost to follow-up do not vary by treatment arm. In total, we have endline haemoglobin concentration data for 2,321 children and endline utilisation data for 2,319 children.

Table A1 in the Appendix compares anaemia outcomes and characteristics of the households in our sample at baseline with the observational arm and the rural sample of Ghana's nationally representative Demographic and Health Survey (DHS) 2008. Almost 40 percent of children in the study sample had anaemia at baseline. One third of mothers have no education, the majority of households are Christian and the predominant ethnicity in this region is Dangme. As expected, there are differences between the study sample and the observational arm. Specifically, those who self-enrolled into the prepayment insurance scheme are healthier and socioeconomically better off. There are also differences between the study sample and the national rural sample from the DHS. Anaemia is less prevalent in the study sample. There is greater ownership of assets but also a greater proportion of un-educated mothers in the study sample.

\footnotetext{
${ }^{7}$ The sample size was calculated to allow detection of an absolute difference of $0.3 \mathrm{~g} / \mathrm{dl}$ in mean haemoglobin concentration between the two treatment arms with a power of 90 percent at a significance level of 5 percent, allowing for loss to follow-up and clustering of children within the same household (Ansah et al., 2009).
} 


\section{Empirical Methods}

\section{IV.A Econometric Models}

To measure the overall effect of removing user fees on outcomes, we run regressions of the form:

$$
y_{i h}=\beta_{0}+\beta_{1} T_{h}+X_{i h} \beta_{2}+\varepsilon_{i h}
$$

where $y_{i h}$ is our outcome, a measure of health care use, health status or health care spending, for child $i$ in household $h, T_{h}$ is an indicator equal to one if household $h$ was assigned to free care, and $X_{i h}$ is a set of individual and household characteristics measured at baseline. The covariates include age, education of mother, number of children in the household, household wealth score, and dummies for gender and categories of distance from the nearest health facility, religion and ethnicity. Note that inclusion of the covariates should improve precision but is not needed for an unbiased estimate of the treatment effect due to the randomised design. We show results with and without these controls. Since there was full compliance with assignment, we are estimating the average treatment effect on the treated. In all specifications, we cluster the standard errors at the household level to deal with correlation between children in the same household and to account for the fact that treatment assignment was done on a household basis.

The main subgroup analysis uses a classification scheme that divides the sample into two based on whether the child was anaemic at baseline. We classify children as having severe or moderate anaemia if the haemoglobin concentration is less than $10 \mathrm{~g} / \mathrm{dl}$, and no anaemia if the level is $10 \mathrm{~g} / \mathrm{dl}$ or above. Anaemia status provides an objective measure of capacity to benefit pre-randomisation and distinguishes this study from those that use self-reported or subjective measures of health. $^{8}$

Formally, we run the following regression to identify the treatment effect within each subgroup of ill and healthy children:

$$
y_{i h}=\alpha_{0}+\alpha_{1} T_{h} \times A_{i h}+\alpha_{2} T_{h} \times\left(1-A_{i h}\right)+X_{i h} \alpha_{3}+\varepsilon_{i h},
$$

\footnotetext{
8 We note that the data show, as expected, a negative correlation between haemoglobin concentration and various measures of nutritional status (ie. wasting, stunting and underweight) and malaria parasitaemia.
} 
where $A_{i h}$ is a dummy that indicates whether the child was anaemic at baseline and is included in the set of covariates, $X_{i h}$. The effect of removing user fees in each subgroup is given by $\alpha_{1}$ and $\alpha_{2}$ respectively. To explore flexibly the effect of free care on haemoglobin concentration at different levels of the initial distribution, we estimate two separate regressions of endline haemoglobin concentration on baseline values either side of the anaemia cut-off in both treatment and control. We then plot local averages and fitted values from a thirdorder polynomial.

To understand how the intervention worked, we estimate the effect of free care on different sets of outcomes in an attempt to trace its impact along the causal pathway. We also discuss possible channels leading to the reduced form impact of free care in Section VI. For now, we note that because the study selected participants from households who had not enrolled in the prepayment scheme, we identify the effect of moving from no insurance coverage to full coverage.

\section{IV.B Validating the Experimental Design}

We validate the experimental design by investigating treatment-control balance of the covariates in the entire sample of children and in each of the two subgroups of ill and healthy children. Table 1 tests covariate balance by showing the mean value of each variable by intervention group and the $p$ value for treatment and control differences.

Panel A in Table 1 confirms that randomisation resulted in balance across the covariates in the full sample of children enrolled into the study. With the exception of "Dangme" ethnicity, the mean differences are not significant for any of the pre-randomisation covariates or baseline haemoglobin concentration. Panel $\mathrm{B}$ and Panel $\mathrm{C}$ of Table 1 provide evidence that treatment and control groups are also balanced in each of the two subgroups of children with and without anaemia at baseline.

One potential source of concern when it comes to estimation is attrition. We further tested the validity of the experimental design by comparing the balance of baseline covariates on the subsample of children who were followed-up at the study end. We are unable to reject the null of treatment and control balance in the two samples of ill and healthy children. ${ }^{9}$ There are no significant differences between treatment and control in the means of any of the covariates in the sample of children with anaemia at baseline (result not shown). The difference between

9 When we regress the treatment group dummy on the pre-randomisation covariates, the corresponding $\mathrm{F}$ statistics and $p$ values are as follows: for children with anaemia at baseline, $\mathrm{F}$ stat (0.80) and $p$ value (0.6197); and for children with no anaemia at baseline, F stat (1.24) and $p$ value (0.2670). 
intervention groups in initial haemoglobin concentration is borderline significant at the 10 percent level in the sample of children without anaemia. For this reason, we control for baseline haemoglobin concentration as a further robustness check in our health impact equations.

\section{Results}

In Section V.A we examine the behavioural responses to free care, showing that moving from a system of cost-sharing with user fees to one in which care is free at the point of use increases utilisation of primary care services, but only amongst those who were ill at baseline. We then show in Section V.B that these behavioural differences between initially ill and healthy children generate a similar pattern in the effect of free care on endline health status, as measured by anaemia. In Section V.C we extend the analysis, first by quantifying the effect of primary care on anaemia, and then by presenting findings from a set of fully interacted models. Section V.D tests for the presence of ex-ante moral hazard. Finally, in Section V.E we use expenditure data to show that the higher the out-ofpocket spending on health care the greater the effect of removing user fees.

\section{V.A Effect on Use of Curative Care}

We estimate the effect of free health care on use of formal health providers. In presenting the results, we focus on clinics (primary level care). Results for other types of health provider, shown in Table A2 of the Appendix, are discussed below. Table 2 presents the overall effect of removing user fees and point estimates in the two subgroups of children with and without anaemia at baseline. Panel A shows treatment effects at the extensive margin (ie. probability of any visit), analysed using probit estimation with marginal coefficient estimates reported. Panel B shows the effect on the total number of visits per year, estimated by OLS. We report estimates from models with and without demographic controls, both of which produce very similar results.

The overall effect of removing user fees was to increase the likelihood of any clinic visit by 3.7 percentage points or 5.9 percent (panel A, column 1). Across subgroups, however, differential effects emerge. There was a larger, statistically significant effect of free care of 8.9 percentage points or 14.5 percent on children with anaemia at baseline (panel A, column 2). By contrast, the point estimate for children with no anaemia at baseline is both small and statistically insignificant (panel A, column 3). The coefficients in the two subgroups are significantly different from each other at the 5 percent level in both models. To the extent that the absence of anaemia is a good proxy of being healthy, these findings suggest 
that free care did not encourage frivolous use of health services amongst those with no capacity to benefit. ${ }^{10}$

A similar pattern of results emerges when we examine utilisation in terms of total clinic visits per year. Table 2 shows a positive effect of free care on use of primary care in the entire sample of children (panel B, column 1). There was a large impact amongst children with anaemia at baseline (panel B, column 2) but, mirroring the results on the extensive margin, there was no statistically significant effect on use of curative care in the group of children with no anaemia at baseline (panel B, column 3). ${ }^{11}$ The impact estimate of 0.53 clinic visits per year in the group of children with anaemia at baseline is equivalent to a 20 percent increase in utilisation. The coefficients in the two subgroups are borderline significantly different from each other at the 10 percent level. Owing to the skewed nature of the data on total utilisation, we have less statistical precision than on the extensive margin, thus making it more difficult to detect a difference between the two subgroups.

In Table A2 of the appendix, we present estimates of the effect of removing user fees on use of other types of health provider. Free care had no effect on use of public hospitals, both overall and in either of the two subgroups, implying that improvements in care seeking behaviour were limited to primary care services. The findings in panel B of Table A2 suggest that the positive effect of free care on utilisation of clinics was the result of a substitution away from informal drug sellers (private pharmacies).

\section{V.B Effect on Anaemia}

Next we investigate whether the increase in use of curative care in the group of children who were ill at baseline translates into improvements in health status. In Table 3 we present results on both anaemia status (Panel A) and haemoglobin concentration (Panel B). Although our balancing tests suggest the control and treatment groups are similar within the two subgroups, as a robustness check we run a third model in which we control for baseline haemoglobin concentration as well as the usual set of demographics.

Overall, we find that removing user fees had no effect on the proportion of children with anaemia (panel A, column 1) or mean haemoglobin concentration of

\footnotetext{
${ }^{10}$ One caveat to consider is the fact that children in the third observational arm were both healthier and used services more than children in the treatment arm at the endline survey. For obvious reasons such a comparison is problematic but it does raise the possibility that those in the observational arm were over-using services.

${ }^{11}$ Because of the skewed nature of the utilisation data (ie. the number of clinic visits contains many zeros), we also estimated treatment effects using count models. The results from a poisson specification remain qualitatively unchanged (results not shown).
} 
children (panel B, column 1). The failure of the intervention to show an impact on anaemia was not due to inadequate treatment of malaria at health facilities as ACT treatment was introduced prior to the start of the trial and shown during the course of the trial to be effective and widely used. ${ }^{12}$

In line with the previous results on utilisation, free care is shown to reduce the proportion of children with anaemia by almost 6 percentage points or around 16 percent in the group of children who were ill at baseline (panel A, column 2). Estimates are significant at the 10 percent level when controls are included, but not in the baseline model. By contrast, free care had no effect on children with no anaemia at baseline (panel A, column 3). The coefficients in the two subgroups are significantly different from each other at the 10 percent level.

A similar pattern of results is shown in panel B of Table 3 when we consider haemoglobin concentration as the outcome of interest. Free care increased haemoglobin concentration in the children who were anaemic at baseline by 0.20 $\mathrm{d} / \mathrm{gl}$ or 2 percent (panel B, column 2). The estimated effect is larger and has greater precision when controlling for individual-level covariates. There is almost no change in the point estimate when we additionally control for baseline haemoglobin concentration. The point estimate in the group of children with no anaemia at baseline is not significantly different from zero (panel B, column 3). Differences in the coefficients between the two subgroups are statistically significant at the 5 percent level.

It is interesting to note the difference between the relatively small effect of free care on haemoglobin concentration and the larger effect on the proportion of children with anaemia. It suggests that the increase in haemoglobin concentration was focused on children at the threshold of no longer being anaemic. In Figure 1, we plot the distributions of the endline haemoglobin concentration by initial anaemia status to show that this is indeed the case for children with no anaemia at baseline. By contrast, there is no difference in the treatment and control distributions of haemoglobin concentration for children with no anaemia at baseline.

Further graphical evidence in Figure 2 shows that all children with anaemia at baseline benefited from free health care. Following the nonparametric approach taken by Duflo et al (2011), we regress children's endline haemoglobin concentration on their baseline value using a third order polynomial, estimated

\footnotetext{
${ }^{12}$ At endline a total of 101 children with fever or histories of fever had a positive rapid diagnostic test for malaria and were treated with amodiaquine and artesunate. All 86 who were traced 14 days later had cleared their parasitaemia. Only 4 out of 924 study participants tested positive using a dipstick assay for the chloroquine, the drug previously used to treat malaria.
} 
separately either side of the anaemia cut-off value in both treatment and control groups. For children who were anaemic at baseline (ie. left of the vertical red line), fitted values of endline haemoglobin concentration in the free care treatment group are always above those in the control group. However, for children who were not anaemic at baseline (ie. right of the vertical red line), there is no evidence that free care improved health.

A serious concern for the interpretation of the results thus far is the fact that children identified with severe anaemia, fever and parasitaemia in the baseline survey were treated in accordance with local guidelines. While it is highly unlikely that the biological effect of treatment persisted to the endline survey, it is not implausible that parents' increased awareness of the health of their children somehow interacted with the removal of user fees to change health seeking behaviour. In a formal test of this possibility, we exclude from the analysis children with severe anaemia (haemoglobin concentration less than $8 \mathrm{~g} / \mathrm{dl}$ ) at baseline. The results, presented in Appendix A3, indicate that the estimates of effect on utilisation for children with moderate anaemia at baseline are of a similar magnitude to those found in the main analysis. The effect on anaemia also remains positive. ${ }^{13}$ Although by no means definitive given the reduction in sample size, these results suggest that the heterogeneity we identify was not simply a manifestation of the ethics requirement to treat children identified as ill during the baseline survey.

\section{V.C Extensions}

We extend the analysis in several ways. First, we use random assignment of the free care intervention to quantify the effect of curative care at primary health clinics on haemoglobin concentration in the subgroup of children who had anaemia at baseline. We estimate the relationship between haemoglobin concentration and use of curative care by two stage least squares (2SLS), using free care as an instrument for utilisation. Because free care was randomly assigned, it is orthogonal to the error term in the first stage equation. The exclusion restriction requires that free care improves health only through its influence on primary care seeking, an assumption we discuss in Section VI.

Table 4 shows the first stage and second stage results, measuring utilisation in terms of any visit to a clinic. In the first stage we regress use of curative on the indicator for whether the family is assigned to receive free care, with the result in column 1 suggesting that the relationship is strong. Specifically, the coefficient

\footnotetext{
${ }^{13}$ The result on utilisation is the key robustness check here. Compared with the main results, we anticipate a smaller health impact for children with moderate anaemia at baseline because they have a lower capacity to benefit - ie. health care will be more efficacious for those with worse initial health.
} 
estimate is statistically significant in the first stage equation and the $F$-statistic on the instrument is sufficiently strong to avoid bias due to weak instruments (Stock et al., 2002).

Our 2SLS estimate identifies the local average treatment effect (LATE) - that is, the effect of curative care on haemoglobin concentration for those children who increased utilisation when user fees were removed. The LATE is a parameter of policy interest because it applies to the group of individuals who actually changed health seeking behaviour in response to a change in health financing policy. The point estimate in column 2 is positive and statistically significant at the 10 percent level. It suggests that, for children who had anaemia, making at least one visit to a clinic every six months (rather than zero visits) increased a child's haemoglobin concentration by $2.7 \mathrm{~d} / \mathrm{gl}$. Note that the equivalent OLS estimate in column 3 shows little or no relationship between health care use and health status.

In a second extension, we further explore heterogeneity in the impact of free care by estimating fully interacted models, whereby every covariate, not simply anaemia status at baseline, is interacted with the free care assignment variable. These models act as an additional robustness check to test whether it is capacity to benefit or in fact socioeconomic factors that drive the results we obtained previously in Section V.A and V.B. They are also of interest in their own right, as a means to explore heterogeneity across other dimensions.

Table 5 presents the results from two fully interacted models that respectively explore the effect of free care on the number of clinic visits per year and haemoglobin concentration. These results are striking for several reasons. First, observe that differential effects of free care for children who were ill and healthy at baseline become stronger when we control for interactions between treatment and the full set of covariates. Children with anaemia at baseline benefited substantially more than those without anaemia both in terms of improved health care seeking (column 1) and haemoglobin concentration (column 2). The coefficients on the interaction between free care and initial anaemia status in both models are significant with 95 percent confidence.

Next, note that there is little variation across other baseline characteristics. For example, we find no evidence of variation in the effect of free care by household wealth, mother's education, or gender of the child, although coefficients in most cases are (arguably) in the expected direction. Contrary to expectations, the effect of removing user fees was not attenuated by distance. The results suggest that there is variation in the health impact of free care across ethnic groups (column 2), but we have no theoretical understanding of why this might be the case and therefore treat this result with caution. 
Third, for completeness, we examine the impact of free care for subgroups defined according to alternative, albeit less comprehensive and responsive, measures of the child's health status at baseline. These include whether the child tested positive for malaria asexual parasitaemia and whether the child was underweight at baseline. Table A4 in the Appendix shows impact estimates for these two sets of subgroups, with the results indicating that free care did not differentially affect health care utilisation or health status. In no instance are the coefficients for healthy children and those with poor health significantly different from each other at the 10 percent level, as indicated by the $p$ values for the test of equality.

\section{V.D Ex-Ante Moral Hazard}

Throughout the paper we have maintained the assumption that the reduction in the cost of curative care, brought about by the introduction of free care, does not influence behaviour in the prevention of disease. If removing user fees encouraged households to be more careless in the (costly) prevention of malaria, this could in principle increase use of curative care resulting in no net improvement in health. Although it is questionable how plausible the possibility of ex-ante moral hazard is in the context of health care, such behaviour may explain, for example, why removing user fees had no overall effect on haemoglobin concentration despite increasing use of curative care at the primary level. We note that there is considerable disutility associated with being ill and, to the best of our knowledge, there is little evidence of ex-ante moral hazard empirically (Kenkel, 2000; Miller et al., 2009; Newhouse and and the Insurance Experiment Group, 1993).

We test for ex-ante moral hazard by examining the effect of free care on prevention and self-reported illness. Table 6 reports the results for the entire sample of children and for the two subgroups according to anaemia baseline status. The findings in column 1 show that free care had no significant effect overall on preventive behaviours or self-reported episodes of illness (measured using the pictorial diaries supplied to and collected from households on a monthly basis). This remains the case when we stratify the analysis by anaemia status at baseline. None of the point estimates in columns 2 and 3 are significant at the 5 percent level, indicating that free care had no effect on outcomes related to prevention or the onset of illness in either of the subgroups of interest (columns 2 and 3). Taken together, these findings provide evidence that households do not exhibit moral hazard behaviour. 


\section{V.E Effect on Health Care Spending}

One of the primary motivations for removing user fees at the point of service use is to provide financial protection to households against the economic consequences of ill health. We expect free care to insure consumption against health shocks by reducing out-of-pocket health care spending. For risk adverse individuals, the welfare gains of consumption smoothing are greatest when faced with extreme shocks, which are typically associated with acute or prolonged health problems. While we lack data on household consumption and are thus unable to measure directly the welfare consequences of free care, we follow Finkelstein and McKnight (2008) in showing quantile regression estimates of the effect of free care at quantiles of the distribution of out-of-pocket medical care spending.

Table 7 presents the overall effect of free care on out-of-pocket medical care spending and quantile regression estimates. The removal of user fees reduced outof-pocket spending by 2,545 cedis or 20 percent (column 1). The estimate of effect from our preferred model is marginally significant at the 10 percent level (column 2). The quantile regression results show wide variation in the effect of free care that becomes even more obvious when we plot these estimates graphically. Figures 3 and 4 confirm that free care has a negative effect on out-ofpocket medical care spending at all quantiles of the distribution in which spending is greater than zero. The pattern of the point estimates from the quantile regressions show that the absolute effect tends to be greater at higher levels of medical care spending, suggesting that financial protection is particularly effective in reigning in outliers at the highest end of the medical care spending distribution.

We have examined health care spending as a proxy indicator of welfare, an important endpoint in its own right. A complementary view might consider the reduction in the price of health care as an enabling factor to improving access to health services, in which case it is instructive to examine the effect of free care on out-of-pocket spending across the two subgroups of children. Table 8 reports estimates from a subgroup analysis in which total health care spending is the dependent variable. Free care reduced total out-of-pocket spending in the group of children with anaemia at baseline (column 2). Our preferred point estimate indicates a reduction of 5,367 cedis or 37 percent in health care spending. The effect of free care in the group of children with no anaemia at baseline is small and insignificant (column 3). Although the coefficients in the two subgroups are not significantly different from each other, the pattern is consistent with the utilisation results. 


\section{Discussion}

Using a randomised experiment in southern Ghana, we examined the differential effects of removing health care user fees for children who were initially ill and healthy. We found that free care increased use of primary care, lowered out-ofpocket spending and reduced anaemia amongst children who were ill at baseline but generated no benefits for initially healthy children. There was no evidence that free care encouraged frivolous use of services amongst children with no capacity to benefit, and there was no effect on the population under study overall. In this section we discuss the potential channels for the effect of free care, highlight the study limitations and consider the implications of the findings.

\section{VI.A Channels}

In the discussion of potential channels, a useful starting point is the simple causal model of health insurance outlined by Card et al (2009). The removal of user fees provides insurance with certain characteristics, insurance affects health care services and health services affect health. In this simplified model, insurance is made up of different elements that each contribute additively to the reduced form effects of removing user fees. For example, whether the family has any insurance coverage at all and the supply-side incentives faced by providers represent two separate channels through which insurance can influence quality-adjusted health services.

There are several reasons to believe that it was insurance coverage alone that led to the increase in the use of formal health services amongst children who were initially ill. First, because the prepayment insurance scheme paid health providers on a fee-for-service basis, there was little or no change in the incentives they faced. If anything, delays in payment may have dampened incentives to provide quality care for insured individuals. Second, the experiment led to a sharp change in insurance status from no coverage to full coverage for those assigned to the treatment group, which means we do not have to address the issue of some families moving from one type of insurance to another. The effect of free care on use of primary care at the extensive margin was 9 percentage points (Table 2). Given that the maximum contribution of "any insurance coverage" to increased use is 39 percentage points, it is perfectly feasible that coverage alone was responsible for what we observed.

The next question relates to the channels through which health services improved health. The findings show that free care led to a shift in utilisation from informal providers to formal providers rather an increase in the total volume of services. This pattern suggests that the improvement in health was the result of a shift 
towards what are probably higher quality providers. However, it remains unclear what was the relative contribution of primary health care at the extensive and intensive margin.

We can gain further insight by noting that the maximum contribution of use of primary health care at the extensive margin cannot exceed the effect of free care on use of primary care times the average prevalence of anaemia amongst children in the control group since anaemia can at most be reduced to zero. The average prevalence of anaemia is 37 percent in the control group (Table 3) and the utilisation impact for the group of children who were ill at baseline is 9 percentage points (Table 2). The maximum reduction in anaemia attributable to the increase in the number of children using primary care at the extensive margin is therefore 0.032 , about 54 percent of our estimate of effect of free care on anaemia. If we assume that care was not effective in all cases, a reasonable conclusion is that the reduction in anaemia was due in equal measure to increases in the use of primary care at the extensive and intensive margin.

Turning to the IV estimate, our reading of the literature suggests that the effect of primary care on haemoglobin concentration of $2.7 \mathrm{~g} / \mathrm{dl}$ is plausible. ${ }^{14}$ As previously mentioned, before the trial started the study district instituted a policy switch from chloroquine to the more effective amodiaquine plus artesunate as the first line treatment drug for malaria and evidence from the trial shows that chloroquine was being used very little by the end of study.

\section{VI.B Limitations}

There is a natural tendency to overplay the economic significance of positive findings and extrapolate them beyond the study context. We urge caution for a number of reasons. First, a cost-benefit analysis was beyond the scope of the study, thus we are no position to interpret the findings for the purposes of a policymaker who wishes to know whether or not to remove user fees. We could have compared the cost of subsidising the health insurance $(20,000$ cedis per family) as well as the additional cost of increased utilisation with the benefits of improved health and reduced financial stress. Not only do we lack the data for such an analysis, we would have had to make heroic assumptions in the monetisation of the benefits.

Although we are unable to reach strong conclusions as to the economic case for removing user fees, it is important to point out that implementation of large scale

\footnotetext{
${ }^{14}$ Anaemia has causes other than malaria. For example, 10 of the 71 children found to be anaemic at the final survey and tested for alternative causes had hookworm infection, suggesting that malaria treatment may not have been the sole pathway through which primary health care affected anaemia in the group of children who were ill at baseline.
} 
health financing reforms tends to be messy. Our study shows the theoretical potential of removing user fees, but outside the confines of a controlled study, impacts might be slower to surface. The estimated effects, while encouraging, are reasonably modest in magnitude and are unlikely to imply that removing user fees will be the magic bullet to improving population health in low-income countries as argued by some commentators. At the same time, we are aware of few experimental or quasi-experimental studies that have shown any health benefit of removing user fees in a developing country.

A second caveat is that the results from the study do not capture general equilibrium effects which may take hold through changes in supply side behaviours when user fees are removed at scale. For example, an increase in health care use, if poorly anticipated, might put pressure on health providers, leading to a reduction in quality of care. A related issue is whether capacity to benefit is a generalisable mechanism through which health insurance and similar health financing tools work. The development of theory might shed some light on this question but empirically it will always be difficult to test because researchers are unable (ethically) to manipulate initial health status of a study population. Thus results such as those from the fully interacted models in Table 5 should be treated with reasonable caution, for heterogeneity may be driven by unobservables that are correlated with capacity to benefit. We believe the most promising way forward is to examine the role of capacity to benefit in different settings.

A third set of limitations relate to the usual concerns about the peculiarities of the study setting. Here we highlight just two factors that limit the generalisability of the findings. In settings where drug quality is lower - for example, if ineffective antimalarial drugs are in use - an increase in utilisation from the removal of user fees may not result in health improvements. Where health worker absenteeism is more common, we are likely to see less of an effect on health care utilisation, owing to supply side constraints.

\section{VI.C Implications}

The three most important findings of this study are that the introduction of free healthcare in this rural developing country context did not increase frivolous use of services by those with better health status at baseline, that there was a benefit to health in those with greatest capacity to benefit (the least healthy) at baseline, and that there was no effect, either positive or negative, on the study population as a whole. These data, in this context, are therefore reassuring on some of the greatest concerns around introducing free health care, and in particular that those who most need care will not benefit, or that there will be a marked increase in frivolous use. The lack of a significant impact on the population as a whole however means the study cannot lend unqualified support to free health care. The key question of 
whether free care is cost-effective, as compared to other policies to improve health, remains elusive. In Ghana, where the insurance scheme tested in this experiment has now been expanded nationwide, these issues may be of particular relevance when considering the overall cost of the scheme, and how to secure its financial sustainability.

This study demonstrates the clear importance of going beyond utilisation to measure health outcomes in the evaluation of health policy. When pathways are short and well established, it may be sufficient to measure health care use. However, when the causal chain is complex and poorly understood, it is vital to measure outcomes that reflect the ultimate objective of the policy. This will generally be the case when conducting research on broad health financing initiatives.

A key lesson for future research, and one that concurs with the conclusions offered by Card et al (2009), is that identifying an effect of health financing reforms on health status is challenging. Changes in health outcomes can be expected to be too subtle to detect across an entire population, in which case research should focus on a subgroup of the population with the greatest capacity to benefit. Progress will require ambitious research designs that are powered to capture changes in multiples dimension of health. 


\section{References}

Agyepong, I. A. and S. Adjei (2008). 'Public social policy development and implementation: a case study of the Ghana National Health Insurance scheme', Health Policy Plan, vol. 23(2), pp. 150-160.

Akin, J., N. Birdsall and D. de Ferranti (1987). Financing health services in developing countries: an agenda for reform, Washington DC: World Bank.

Ansah, E. K., S. Narh-Bana, S. Asiamah, V. Dzordzordzi, K. Biantey, K. Dickson, J. O. Gyapong, K. A. Koram, B. M. Greenwood, A. Mills and C. J. Whitty (2009). 'Effect of removing direct payment for health care on utilisation and health outcomes in Ghanaian children: a randomised controlled trial', PLoS Med, vol. 6(1).

Arrow, K. (1963). 'Uncertainty and the Welfare Economics of Medical Care', The American Economic Review, vol. 53, pp. 941-973.

Asenso-Okyere, W. K. and J. A. Dzator (1997). 'Household cost of seeking malaria care. A retrospective study of two districts in Ghana', Soc Sci Med, vol. 45(5), pp. 659-667.

Ashraf, N., J. Berry and J. M. Shapiro (2010). 'Can Higher Prices Stimulate Product Use? Evidence from a Field Experiment in Zambia', American Economic Review, vol. 100(5), pp. 2383-2413.

Atim, C. (2010). 'Ghana's National Health Insurance Scheme', in (Escobar, M. L., C. Griffin and P. Shaw Eds.), Impact of Health Insurance in Low and Middle Income Countries, Washington DC: Brookings Institution Press.

Card, D., C. Dobkin and N. Maestas (2009). 'Does Medicare Save Lives?', Quarterly Journal of Economics, vol. 124(2), pp. 597-636.

Cohen, J. and P. Dupas (2010). 'Free Distribution or Cost-Sharing? Evidence from a Randomized Malaria Prevention Experiment', Quarterly Journal of Economics, vol. 125(1), pp. 1-45.

Commission for Africa (2005). Our common interest: report of the Commission for Africa, London: Commission for Africa.

Creese, A. L. (1991). 'User charges for health care: a review of recent experience', Health Policy Plan, vol. 6(4), pp. 309-319.

Culyer, A. J. (1995). 'Need: the idea won't do--but we still need it', Soc Sci Med, vol. 40(6), pp. 727-730.

Culyer, A. J. and H. Simpson (1980). 'Externality Models and Health - a Ruckblick over the Last 20 Years', Economic Record, vol. 56(154), pp. 222-230.

DeMaeyer, E. (1989). Preventing and controlling iron deficiency anaemia through primary health care: A guide for health administrators and programme managers, Geneva: World Health Organization.

Duflo, E., P. Dupas and M. Kremer (2011). 'Peer Effects, Teacher Incentives, and the Impact of Tracking: Evidence from a Randomized Evaluation in Kenya', American Economic Review, vol. 101(5), pp. 1739-1774.

Finkelstein, A. and R. McKnight (2008). 'What did Medicare do? The initial impact of Medicare on mortality and out of pocket medical spending', Journal of Public Economics, vol. 92(7), pp. 1644-1668.

Gertler, P. and J. Gruber (2002). 'Insuring consumption against illness', American Economic Review, vol. 92(1), pp. 51-70. 
Ghana Statistical Service, Ghana Health Service and ICF Macro (2009). Ghana Demographic and Health Survey 2008, Accra, Ghana: Government of Ghana.

Gilson, L. and D. McIntyre (2005). 'Removing user fees for primary care in Africa: the need for careful action', BMJ, vol. 331(7519), pp. 762-765.

Jones, G., R. W. Steketee, R. E. Black, Z. A. Bhutta and S. S. Morris (2003). 'How many child deaths can we prevent this year?', Lancet, vol. 362(9377), pp. 65-71.

Kenkel, D. (2000). 'Prevention', in (Culyer, A. J. and J. Newhouse Eds.), Handbook of Health Economics Vol. 1, Amsterdam: Elsevier.

King, G., E. Gakidou, K. Imai, J. Lakin, R. T. Moore, C. Nall, N. Ravishankar, M. Vargas, M. M. Tellez-Rojo, J. E. Avila, M. H. Avila and H. H. Llamas (2009). 'Public policy for the poor? A randomised assessment of the Mexican universal health insurance programme', Lancet, vol. 373(9673), pp. 1447-1454.

Kremer, M. and E. Miguel (2007). 'The illusion of sustainability', Quarterly Journal of Economics, vol. 122(3), pp. 1007-1065.

Lagarde, M. and N. Palmer (2008). 'The impact of user fees on health service utilization in low- and middle-income countries: how strong is the evidence?', Bull World Health Organ, vol. 86(11), pp. 839-848.

Manning, W. G., J. P. Newhouse, N. Duan, E. B. Keeler, A. Leibowitz and M. S. Marquis (1987). 'Health-Insurance and the Demand for Medical-Care Evidence from a Randomized Experiment', American Economic Review, vol. 77(3), pp. 251-277.

Miller, G., D. M. Pinto and M. Vera-Hernandez (2009) High-Powered Incentives in Developing Country Health Insurance Evidence from Colombia's Regimen Subsidiado, Cambridge, MA, National Bureau of Economic Research. Available at http://www.nber.org/papers/w15456.

Morduch, J. (1995). 'Income Smoothing and Consumption Smoothing', Journal of Economic Perspectives, vol. 9(3), pp. 103-114.

Newhouse, J. (2002). Pricing the Priceless - A Health Care Conundrum, Cambridge, MA: MIT Press.

Newhouse, J. and and the Insurance Experiment Group (1993). Free for All? Lessons from the RAND Health Insurance Experiment, Cambridge, MA: Harvard University Press.

Nyman, J. A. (1999). 'The value of health insurance: the access motive', Journal of Health Economics, vol. 18(2), pp. 141-152.

Pauly, M. (1968). 'The Economics of Moral Hazard', American Economic Review, vol. 49, pp. 531-537.

Pauly, M. (1983). 'More on Moral Hazard', Journal of Health Economics, vol. 2(1), pp. 81-85.

Phelps, C. (1978). 'Illness Prevention and Medical Insurance', Journal of Human Resources, vol. 13, pp. 183-207.

Pitt, M. M. and S. R. Khandker (1998). 'The impact of group-based credit programs on poor households in Bangladesh: Does the gender of participants matter?', Journal of Political Economy, vol. 106(5), pp. 958996.

Stock, J. H., J. H. Wright and M. Yogo (2002). 'A survey of weak instruments and weak identification in generalized method of moments', Journal of Business \& Economic Statistics, vol. 20(4), pp. 518-529. 
Thornton, R. L. (2008). 'The Demand for, and Impact of, Learning HIV Status', American Economic Review, vol. 98(5), pp. 1829-1863.

Thornton, R. L., L. E. Hatt, E. M. Field, M. Islam, F. S. Diaz and M. A. Gonzalez (2010). 'Social security health insurance for the informal sector in Nicaragua: a randomized evaluation', Health Econ, vol. 19 Suppl, pp. 181206.

van Doorslaer, E., O. O'Donnell, R. P. Rannan-Eliya, A. Somanathan, S. R. Adhikari, C. C. Garg, D. Harbianto, A. N. Herrin, M. N. Huq, S. Ibragimova, A. Karan, T. J. Lee, G. M. Leung, J. F. Lu, C. W. Ng, B. R. Pande, R. Racelis, S. Tao, K. Tin, K. Tisayaticom, L. Trisnantoro, C. Vasavid and Y. Zhao (2007). 'Catastrophic payments for health care in Asia', Health Econ, vol. 16(11), pp. 1159-1184.

Waddington, C. and K. A. Enyimayew (1989). 'A price to pay: The impact of user charges in Ashanti-Akim district, Ghana', International Journal of Health Planning and Management, vol. 4(1), pp. 17-47.

Waddington, C. and K. A. Enyimayew (1990). 'A price to pay, part 2: The impact of user charges in the Volta region of Ghana', International Journal of Health Planning and Management, vol. 5(4), pp. 287-312.

World Health Organization (2010). The world health report - Health systems financing: the path to universal coverage, Geneva: World Health Organization.

Yates, R. (2009). 'Universal health care and the removal of user fees', Lancet, vol. 373(9680), pp. 2078-2081.

Zeckhauser, R. (1970). 'Medical Insurance - Case Study of Tradeoff between Risk Spreading and Appropriate Incentives', Journal of Economic Theory, vol. 2(1), pp. 10-26. 
TABLE 1

VALIDATING RANDOMISATION

\begin{tabular}{|c|c|c|c|c|}
\hline & \multirow{3}{*}{$\begin{array}{l}\text { Mean in } \\
\text { treatment group } \\
\text { (1) }\end{array}$} & \multirow{3}{*}{$\begin{array}{c}\text { Mean in } \\
\text { control group } \\
\text { (2) }\end{array}$} & \multicolumn{2}{|c|}{ Difference } \\
\hline & & & Mean & $\mathrm{p}$-value \\
\hline & & & (3) & (4) \\
\hline \multicolumn{5}{|c|}{ Panel A: Full Sample of Households } \\
\hline Mother's education (years) & 5.345 & 5.183 & -0.162 & 0.390 \\
\hline Children in household & 1.318 & 1.312 & -0.006 & 0.810 \\
\hline Male child & 0.508 & 0.499 & -0.009 & 0.680 \\
\hline Distance from health centre $5-10 \mathrm{~km}$ & 0.210 & 0.199 & -0.010 & 0.550 \\
\hline Distance from health centre $>10 \mathrm{~km}$ & 0.158 & 0.158 & 0.000 & 1.000 \\
\hline Age of child (months) & 32.867 & 32.002 & -0.865 & 0.200 \\
\hline Wealth asset score & -0.018 & 0.022 & 0.039 & 0.610 \\
\hline Christian religion & 0.882 & 0.873 & -0.009 & 0.530 \\
\hline Dangme ethnicity & 0.660 & 0.624 & $-0.036 *$ & 0.081 \\
\hline Haemoglobin concentration $(\mathrm{g} / \mathrm{dl})$ & 10.354 & 10.324 & -0.030 & 0.660 \\
\hline \multicolumn{5}{|c|}{ Panel B: Sample of Households with Anaemic Child at Baseline } \\
\hline Mother's education (years) & 4.725 & 4.868 & 0.143 & 0.628 \\
\hline Children in household & 1.352 & 1.329 & -0.024 & 0.570 \\
\hline Male child & 0.522 & 0.482 & -0.040 & 0.260 \\
\hline Distance from health centre $5-10 \mathrm{~km}$ & 0.219 & 0.213 & -0.006 & 0.843 \\
\hline Distance from health centre $>10 \mathrm{~km}$ & 0.149 & 0.170 & 0.021 & 0.413 \\
\hline Age of child (months) & 29.764 & 28.369 & -1.395 & 0.185 \\
\hline Wealth asset score & -0.395 & -0.254 & 0.141 & 0.182 \\
\hline Christian religion & 0.851 & 0.856 & 0.005 & 0.844 \\
\hline Dangme ethnicity & 0.653 & 0.636 & -0.017 & 0.613 \\
\hline Haemoglobin concentration $(\mathrm{g} / \mathrm{dl})$ & 8.778 & 8.682 & -0.096 & 0.190 \\
\hline \multicolumn{5}{|c|}{ Panel C: Sample of Households without Anaemic Child at Baseline } \\
\hline Mother's education (years) & 5.708 & 5.381 & -0.327 & 0.177 \\
\hline Children in household & 1.298 & 1.302 & 0.004 & 0.891 \\
\hline Male child & 0.500 & 0.510 & 0.010 & 0.725 \\
\hline Distance from health centre $5-10 \mathrm{~km}$ & 0.205 & 0.191 & -0.014 & 0.529 \\
\hline Distance from health centre $>10 \mathrm{~km}$ & 0.163 & 0.150 & -0.013 & 0.512 \\
\hline Age of child (months) & 34.685 & 34.279 & -0.407 & 0.632 \\
\hline Wealth asset score & 0.203 & 0.194 & -0.009 & 0.933 \\
\hline Christian religion & 0.901 & 0.884 & -0.016 & 0.340 \\
\hline Dangme ethnicity & 0.664 & 0.616 & $-0.048^{*}$ & 0.068 \\
\hline Haemoglobin concentration $(\mathrm{g} / \mathrm{dl})$ & 11.277 & 11.352 & 0.075 & 0.133 \\
\hline
\end{tabular}

Notes: $* * *$ denotes significance at $1 \%, * *$ at $5 \%$, and $*$ at $10 \%$ level for the test of equality of means. There are 2,151 households in the full sample, 812 households in the sample with anaemic child, and 1,339 households in the sample without anaemic child. 
TABLE 2

EFFECT OF FREE CARE ON USE OF PRIMARY HEALTH SERVICES

\begin{tabular}{|c|c|c|c|c|}
\hline & \multirow{2}{*}{$\begin{array}{c}\text { Full sample of } \\
\text { children }\end{array}$} & \multicolumn{2}{|c|}{ By anaemia status at baseline } & \multirow{2}{*}{$\begin{array}{c}\text { Test } \\
\text { (ill=healthy) } \\
\text { p-value }\end{array}$} \\
\hline & & $\begin{array}{l}\text { Anaemic } \\
\text { (ill) }\end{array}$ & $\begin{array}{c}\text { Not anaemic } \\
\text { (healthy) }\end{array}$ & \\
\hline & (1) & $(2)$ & (3) & $(4)$ \\
\hline \multicolumn{5}{|c|}{ Panel A: Any clinic visit as dependent variable (extensive margin) } \\
\hline Control mean & 0.629 & 0.614 & 0.639 & \\
\hline \multicolumn{5}{|l|}{ Model: } \\
\hline \multirow[t]{2}{*}{ Baseline } & 0.037 & 0.089 & 0.004 & 0.031 \\
\hline & $(0.021)^{*}$ & $(0.030) * * *$ & $(0.026)$ & \\
\hline \multirow[t]{2}{*}{ Baseline + demographics } & 0.036 & 0.087 & 0.002 & 0.035 \\
\hline & $(0.021)^{*}$ & $(0.031) * * *$ & $(0.026)$ & \\
\hline Number of children & 2,319 & 892 & 1,427 & \\
\hline \multicolumn{5}{|c|}{ Panel B: Clinic visits per year as dependent variable } \\
\hline Control mean & 2.516 & 2.448 & 2.560 & \\
\hline \multicolumn{5}{|l|}{ Model: } \\
\hline \multirow[t]{2}{*}{ Baseline } & 0.298 & 0.559 & 0.138 & 0.089 \\
\hline & $(0.128) * *$ & $(0.205) * * *$ & $(0.155)$ & \\
\hline \multirow[t]{2}{*}{ Baseline + demographics } & 0.286 & 0.525 & 0.136 & 0.113 \\
\hline & $(0.127)^{* *}$ & $(0.203) * * *$ & $(0.153)$ & \\
\hline Number of children & 2,319 & 892 & 1,427 & \\
\hline
\end{tabular}

Notes: $* * *$ denotes significance at $1 \%, * *$ at $5 \%$, and $*$ at $10 \%$ level. Standard errors, corrected for clustering at the household level, are reported in parentheses. Regressions in Panel A use probit estimation with marginal coefficient estimates reported. Regressions in Panel B are estimated by OLS. Demographics include controls for mother's education, number of children in household, age of the child, household wealth and dummies for male child, distance from the nearest health centre, Christian religion and Dangme ethnicity. Anaemia is defined as having a haemoglobin concentration of less than $10 \mathrm{~d} / \mathrm{gl}$. 
TABLE 3

EFFECT OF FREE CARE ON ANAEMIA OUTCOMES

\begin{tabular}{|c|c|c|c|c|}
\hline & \multirow{2}{*}{$\begin{array}{l}\text { Full sample of } \\
\text { children }\end{array}$} & \multicolumn{2}{|c|}{ By anaemia status at baseline } & \multirow{2}{*}{$\begin{array}{c}\text { Test } \\
\text { (ill=healthy) } \\
p \text {-value }\end{array}$} \\
\hline & & $\begin{array}{l}\text { Anaemic } \\
\text { (ill) }\end{array}$ & $\begin{array}{l}\text { Not anaemic } \\
\text { (healthy) }\end{array}$ & \\
\hline & (1) & $(2)$ & (3) & (4) \\
\hline \multicolumn{5}{|c|}{ Panel A: Anaemic as dependent variable } \\
\hline Control mean & 0.238 & 0.373 & 0.151 & \\
\hline \multicolumn{5}{|l|}{ Model: } \\
\hline \multirow[t]{2}{*}{ Baseline } & -0.017 & -0.052 & 0.009 & 0.106 \\
\hline & $(0.018)$ & $(0.032)$ & $(0.019)$ & \\
\hline \multirow[t]{2}{*}{ Baseline + demographics } & -0.016 & -0.060 & 0.012 & 0.077 \\
\hline & $(0.018)$ & $(0.033)^{*}$ & $(0.019)$ & \\
\hline \multirow[t]{2}{*}{ Baseline + demographics + initial $\mathrm{Hb}$} & -0.016 & -0.059 & 0.010 & 0.093 \\
\hline & $(0.017)$ & $(0.033) *$ & $(0.019)$ & \\
\hline Number of children & 2,321 & 892 & 1,429 & \\
\hline \multicolumn{5}{|c|}{ Panel B: Haemoglobin level as dependent variable } \\
\hline Control mean & 11.015 & 10.418 & 11.399 & \\
\hline \multicolumn{5}{|l|}{ Model: } \\
\hline \multirow[t]{2}{*}{ Baseline } & 0.047 & 0.202 & -0.071 & 0.039 \\
\hline & $(0.067)$ & $(0.109)^{*}$ & $(0.078)$ & \\
\hline \multirow[t]{2}{*}{ Baseline + demographics } & 0.048 & 0.219 & -0.072 & 0.024 \\
\hline & $(0.066)$ & $(0.106) * *$ & $(0.077)$ & \\
\hline \multirow[t]{2}{*}{ Baseline + demographics + initial $\mathrm{Hb}$} & 0.047 & 0.215 & -0.062 & 0.031 \\
\hline & $(0.063)$ & $(0.105) * *$ & $(0.076)$ & \\
\hline Number of children & 2,321 & 892 & 1,429 & \\
\hline
\end{tabular}

Notes: $* * *$ denotes significance at $1 \%, * *$ at $5 \%$, and $*$ at $10 \%$ level. Standard errors, corrected for clustering at the household level, are reported in parentheses. Regressions in Panel A use probit estimation with marginal coefficient estimates reported. Regressions in Panel B are estimated by OLS. Demographics include controls for mother's education, number of children in household, age of the child, household wealth and dummies for male child, distance from the nearest health centre, Christian religion and Dangme ethnicity. Anaemia is defined as having a haemoglobin concentration of less than $10 \mathrm{~d} / \mathrm{gl}$. 
FIGURE 1

\section{Distribution of HaEmoglobin ConCENTRATION by BaSEline ANAEMia Status}
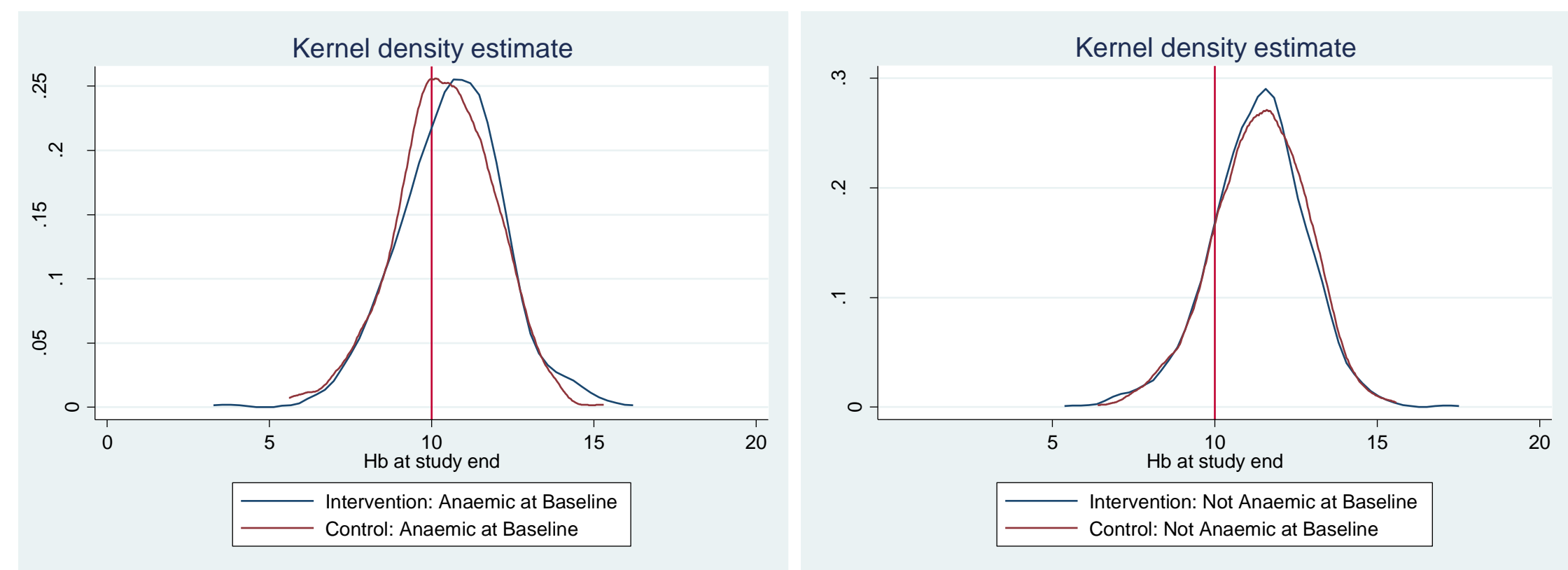

Notes: Figure 1 plots kernel density estimates using an epanechnikov kernel function and an optimal bandwidth. The vertical red line represents the haemoglobin concentration threshold used to define anaemia status - ie. children to the left of the line are anaemic. 
FIGURE 2

Local Average EFFeCT WITH POLYNOMIAL Fit

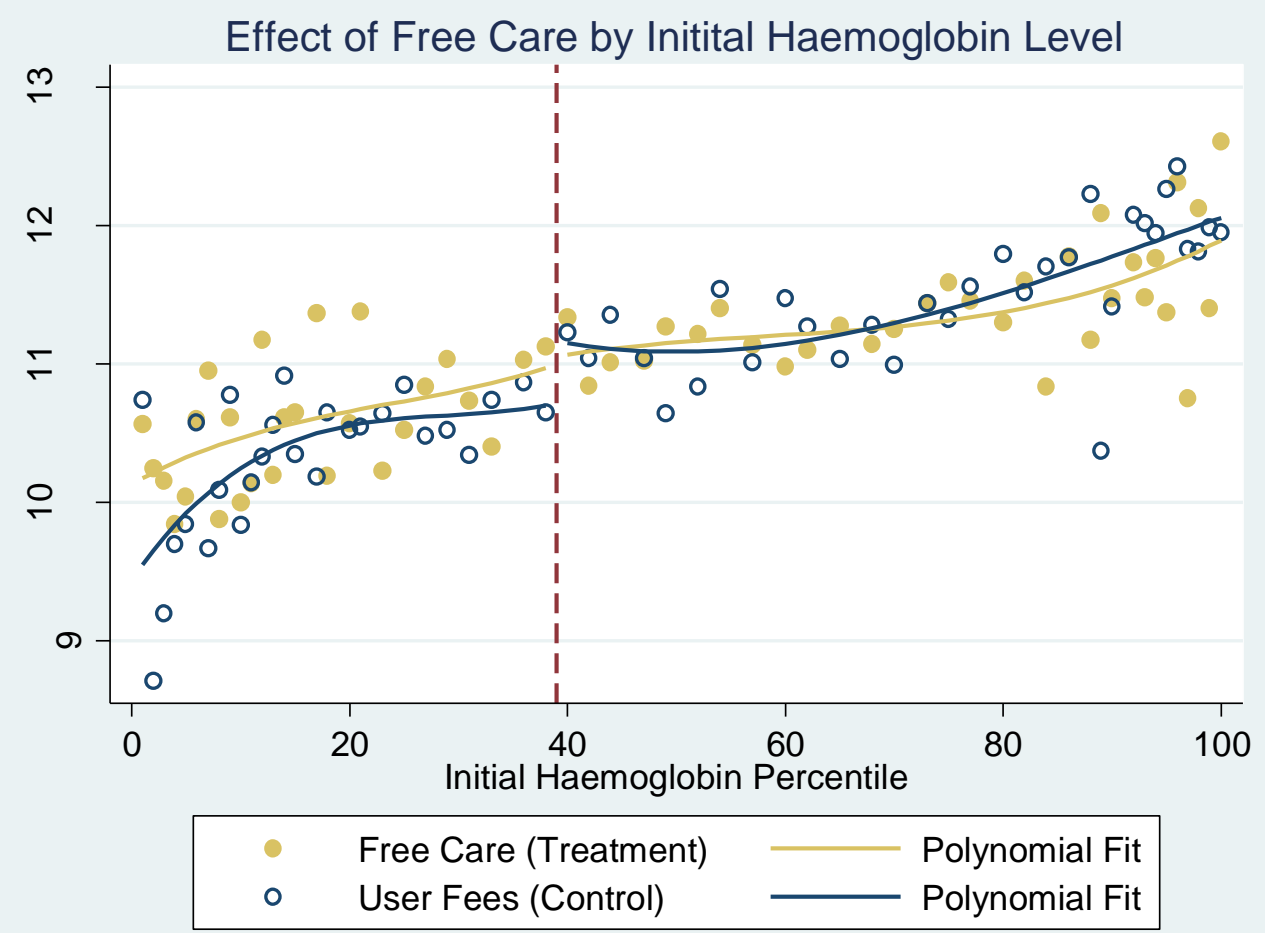

Notes: The fitted values are from regressions in which a third order polynomial is estimated separately on each side of the haemoglobin concentration threshold of $10 \mathrm{~g} / \mathrm{dl}$, used to define anaemia. The points are local averages at each percentile of the initial haemoglobin percentile. 
TABLE 4

QuANTIFYING THE EFFeCT OF HeAlth CARE ON HeAlth OUTCOMES

\begin{tabular}{|c|c|c|c|}
\hline & \multicolumn{3}{|c|}{ Effect of any clinic visit } \\
\hline & $\begin{array}{l}\text { Any clinic visit } \\
\left(1^{\text {st }} \text { stage }\right)\end{array}$ & $\begin{array}{c}\text { Haemoglobin } \\
\text { concentration } \\
\left(2^{\text {nd }} \text { stage }\right)\end{array}$ & $\begin{array}{c}\text { Haemoglobin } \\
\text { concentration } \\
\left(2^{\text {nd }} \text { stage }\right)\end{array}$ \\
\hline & OLS & IV & OLS \\
\hline & (1) & (2) & (3) \\
\hline \multirow[t]{2}{*}{ Free care treatment } & 0.085 & & \\
\hline & $(0.032) * * *$ & & \\
\hline \multirow[t]{2}{*}{ Any clinic visit } & & 2.654 & 0.022 \\
\hline & & $(1.604) *$ & \\
\hline Demographics & YES & YES & YES \\
\hline$F(1,742)$ on instrument & 7.25 & - & - \\
\hline$p$ value & $(0.007)$ & - & - \\
\hline Number of children & 892 & 892 & 892 \\
\hline
\end{tabular}

Notes: $* * *$ denotes significance at $1 \%, * *$ at $5 \%$, and $*$ at $10 \%$ level. Standard errors, corrected for clustering at the household level, are reported in parentheses. The sample used in this analysis is children who were anaemic at baseline. 
TABLE 5

FULLY INTERACTED MODELS

\begin{tabular}{|c|c|c|}
\hline & $\begin{array}{c}\text { Clinic visits per } \\
\text { year } \\
(1)\end{array}$ & $\begin{array}{c}\text { Haemoglobin } \\
\text { concentration } \\
\text { (2) }\end{array}$ \\
\hline \multirow[t]{2}{*}{ Free care } & -0.200 & -0.268 \\
\hline & $(0.576)$ & $(0.311)$ \\
\hline \multirow[t]{2}{*}{ Anaemia $\times$ free care treatment } & 0.498 & 0.278 \\
\hline & $(0.249)^{* *}$ & $(0.133) * *$ \\
\hline \multirow[t]{2}{*}{ Mother's education $\times$ free care treatment } & 0.013 & 0.005 \\
\hline & $(0.032)$ & $(0.016)$ \\
\hline \multirow[t]{2}{*}{ Children in household $\times$ free care treatment } & -0.197 & -0.008 \\
\hline & $(0.214)$ & $(0.102)$ \\
\hline \multirow[t]{2}{*}{ Boy $\times$ free care treatment } & 0.108 & -0.162 \\
\hline & $(0.233)$ & $(0.123)$ \\
\hline \multirow[t]{2}{*}{ Distance health centre $5 \geq 10 \mathrm{~km} \times$ free care treatment } & 0.597 & 0.016 \\
\hline & $(0.316)^{*}$ & $(0.161)$ \\
\hline \multirow[t]{2}{*}{ Distance health centre $>10 \mathrm{~km} \times$ free care treatment } & 0.171 & 0.132 \\
\hline & $(0.327)$ & $(0.188)$ \\
\hline \multirow[t]{2}{*}{ Age of child $\times$ free care treatment } & 0.004 & -0.001 \\
\hline & $(0.007)$ & $(0.004)$ \\
\hline \multirow[t]{2}{*}{ Asset wealth $\times$ free care treatment } & 0.122 & -0.036 \\
\hline & $(0.075)$ & $(0.037)$ \\
\hline \multirow[t]{2}{*}{ Christian (religion) $\times$ free care treatment } & 0.357 & 0.097 \\
\hline & $(0.374)$ & $(0.206)$ \\
\hline \multirow[t]{2}{*}{ Dangme (ethnicity) $\times$ free care treatment } & -0.209 & 0.265 \\
\hline & $(0.269)$ & $(0.134) * *$ \\
\hline Number of children & 2,319 & 2,321 \\
\hline R squared & 0.039 & 0.114 \\
\hline
\end{tabular}

Notes: $* * *$ denotes significance at $1 \%, * *$ at $5 \%$, and $*$ at $10 \%$ level. Standard errors, corrected for clustering at the household level, are reported in parentheses. Regressions are estimated by OLS. All models include a set of demographics that control for mother's education, number of children in household, age of the child, household wealth and dummies for male child, distance from the nearest health centre, Christian religion and Dangme ethnicity. The models also include a full set of interactions between free care and the demographics. Only the coefficients on the interactions are reported. 
TABLE 6

FreE CARE AND EX-ANTE Moral HaZARD

\begin{tabular}{|c|c|c|c|c|}
\hline & \multirow{2}{*}{$\begin{array}{l}\text { Full sample of } \\
\text { children }\end{array}$} & \multicolumn{2}{|c|}{ By anaemia status at baseline } & \multirow{2}{*}{$\begin{array}{c}\text { Test } \\
\text { (ill=healthy) } \\
p \text {-value }\end{array}$} \\
\hline & & $\begin{array}{l}\text { Anaemic } \\
\text { (ill) }\end{array}$ & $\begin{array}{l}\text { Not anaemic } \\
\text { (healthy) }\end{array}$ & \\
\hline & (1) & $(2)$ & (3) & (4) \\
\hline \multicolumn{5}{|c|}{ Panel A: Preventive behaviours } \\
\hline \multirow[t]{3}{*}{ Slept under bed net last night } & 0.004 & -0.039 & 0.032 & 0.074 \\
\hline & $(0.022)$ & $(0.031)$ & $(0.028)$ & \\
\hline & [0.316] & [0.362] & [0.286] & \\
\hline \multirow[t]{3}{*}{ Slept under bed net last 7 nights } & 0.026 & -0.009 & 0.051 & 0.116 \\
\hline & $(0.021)$ & $(0.030)$ & $(0.026)^{*}$ & \\
\hline & [0.252] & {$[0.286]$} & [0.231] & \\
\hline \multirow[t]{3}{*}{ Any malaria prevention measure } & 0.007 & 0.026 & -0.007 & 0.222 \\
\hline & $(0.015)$ & $(0.021)$ & $(0.019)$ & \\
\hline & [0.862] & {$[0.848]$} & {$[0.871]$} & \\
\hline \multicolumn{5}{|c|}{ Panel B: Onset of illness } \\
\hline \multirow[t]{3}{*}{ Ill past 6 months } & 0.014 & 0.018 & 0.011 & 0.726 \\
\hline & $(0.011)$ & $(0.015)$ & $(0.014)$ & \\
\hline & [0.928] & {$[0.934]$} & [0.924] & \\
\hline \multirow[t]{3}{*}{ Episodes of illness past 6 months } & -0.444 & -0.177 & -0.602 & 0.523 \\
\hline & $(0.340)$ & $(0.552)$ & $(0.410)$ & \\
\hline & [9.774] & {$[10.222]$} & [9.486] & \\
\hline \multirow[t]{3}{*}{ Episodes of fever past 6 months } & -0.223 & -0.212 & -0.220 & 0.981 \\
\hline & $(0.164)$ & $(0.263)$ & $(0.202)$ & \\
\hline & [5.551] & [5.794] & [5.395] & \\
\hline
\end{tabular}

Notes: $* * *$ denotes significance at $1 \%, * *$ at $5 \%$, and $*$ at $10 \%$ level. Standard errors, corrected for clustering at the household level, are reported in parentheses. The mean of the dependent variable in the control group is reported in square brackets. Regressions in Panel A use probit estimation with marginal coefficient estimates reported. Regressions in Panel B are estimated by OLS. Demographics include controls for mother's education, number of children in household, age of the child, household wealth and dummies for male child, distance from the nearest health centre, Christian religion and Dangme ethnicity. Anaemia is defined as having a haemoglobin concentration of less than $10 \mathrm{~d} / \mathrm{gl}$. 
TABLE 7

QuANTILE REgRession Estimates of EFFECT OF FreE CARE ON OUT-OF-PoCKET

HEALTH CARE SPENDING

\begin{tabular}{|c|c|c|c|}
\hline & $\begin{array}{l}\text { OLS baseline } \\
\text { (1) }\end{array}$ & $\begin{array}{c}\text { OLS baseline with } \\
\text { demographics } \\
(2)\end{array}$ & $\begin{array}{c}\text { Quantile } \\
\text { (3) }\end{array}$ \\
\hline \multicolumn{4}{|c|}{ Panel A: Out-of-pocket health spending as dependent variable } \\
\hline Average treatment effect & $\begin{array}{l}-2545 \\
(1586)\end{array}$ & $\begin{array}{c}-2678 \\
(1560)^{*}\end{array}$ & \\
\hline Q60 & & & $\begin{array}{c}0 \\
(107)\end{array}$ \\
\hline Q70 & & & $\begin{array}{c}-2119 \\
(1248)^{*}\end{array}$ \\
\hline Q80 & & & $\begin{array}{c}-3619 \\
(1767)^{* *}\end{array}$ \\
\hline Q90 & & & $\begin{array}{c}-6992 \\
(2701) * * *\end{array}$ \\
\hline Control mean & 12,899 & 12,899 & 12,899 \\
\hline Observations & 2,321 & 2,321 & 2,321 \\
\hline
\end{tabular}

Notes: $* * *$ denotes significance at $1 \%, * *$ at $5 \%$, and $*$ at $10 \%$ level. OLS standard errors, corrected for clustering at the household level, are reported in parentheses. Quantile regression standard errors are calculated based on 200 bootstraps. Demographics include controls for mother's education, number of children in household, age of the child, household wealth and dummies for male child, distance from the nearest health centre, Christian religion and Dangme ethnicity. The exchange rate at the time of the study was 16,000 cedis to each $£ 1$. 
FIGURE 3 \& FIGURE 4

\section{EFFeCt of Free HeAlth CARE ON OUT-OF-Pocket SPENDing}
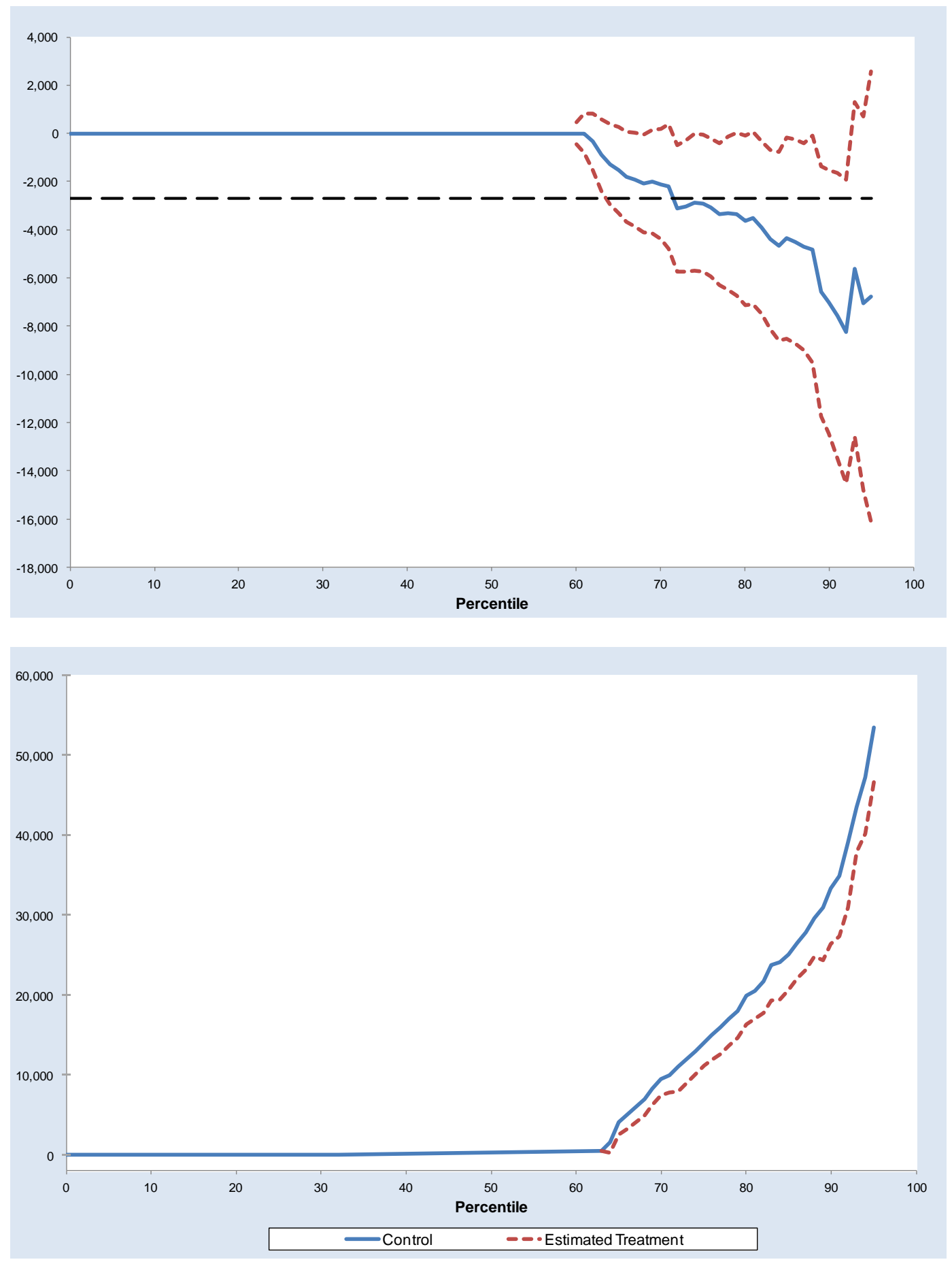

Notes: Figure 3 shows quantile regression estimates of the effect of free care on out-of-pocket spending in the four weeks prior to interview (solid line), with their 95 percent confidence interval (short dashed lines) and the mean effect (long dashed line). Estimates are calculated starting at the smallest percentile with non zero out-of-pocket health spending in either the treatment or control group. Standard errors are estimated via bootstrapping with 200 repetitions. Figure 4 shows the distribution of out-of-pocket spending in the four weeks prior to interview in the control group (solid line) and the estimated distribution in the treatment group (short dashed line), calculated as the sum of the control group and the quantile regression coefficient estimated at each percentile. The quantile regressions include controls for mother's education, number of children in household, age of the child, household wealth and dummies for male child, distance from the nearest health centre, Christian religion, and Dangme ethnicity. 
TABLE 8

EFFECT OF Free CARE ON OUt-OF-Pocket Health CARE SPENDING

\begin{tabular}{|c|c|c|c|c|}
\hline & \multirow{2}{*}{$\begin{array}{c}\text { Full sample of } \\
\text { children } \\
\text { (1) }\end{array}$} & \multicolumn{2}{|c|}{ By anaemia status at baseline } & \multirow{2}{*}{$\begin{array}{c}\text { Test } \\
\text { (ill=healthy) } \\
p \text {-value } \\
(4)\end{array}$} \\
\hline & & $\begin{array}{c}\text { Anaemic } \\
\text { (2) }\end{array}$ & $\begin{array}{c}\text { Not anaemic } \\
\text { (3) }\end{array}$ & \\
\hline Control mean & 12,899 & 14,357 & 11,959 & \\
\hline \multicolumn{5}{|l|}{ Model: } \\
\hline Baseline & $\begin{array}{l}-2,543 \\
(1,586)\end{array}$ & $\begin{array}{c}-5,230 \\
(2,766)^{*}\end{array}$ & $\begin{array}{c}-865 \\
(1,861)\end{array}$ & 0.188 \\
\hline Baseline + demographics & $\begin{array}{c}-2,678 \\
(1,560)^{*}\end{array}$ & $\begin{array}{c}-5,367 \\
(2,773) *\end{array}$ & $\begin{array}{l}-1,001 \\
(1,825)\end{array}$ & 0.188 \\
\hline Number of children & 2,321 & 892 & 1,429 & \\
\hline
\end{tabular}

Notes: $* * *$ denotes significance at $1 \%, * *$ at $5 \%$, and $*$ at $10 \%$ level. Standard errors, corrected for clustering at the household level, are reported in parentheses. Regressions are estimated by OLS. Demographics include controls for mother's education, number of children in household, age of the child, household wealth and dummies for male child, distance from the nearest health centre, Christian religion and Dangme ethnicity. Anaemia is defined as having a haemoglobin concentration of less than $10 \mathrm{~d} / \mathrm{gl}$. The exchange rate at the time of the study was 16,000 cedis to each $£ 1$. 


\section{TABLE A1}

\section{SUMMARY STATISTICS}

\begin{tabular}{|c|c|c|c|}
\hline & $\begin{array}{c}\text { Baseline study } \\
\text { sample }\end{array}$ & $\begin{array}{l}\text { Baseline self- } \\
\text { enrolled sample }\end{array}$ & $\begin{array}{c}\text { Ghana DHS } 2008 \\
\text { (Rural) }\end{array}$ \\
\hline \multicolumn{4}{|c|}{ Panel A: Anaemia Outcomes at Baseline (Children Sample) } \\
\hline \multirow[t]{2}{*}{ Haemoglobin concentration $(\mathrm{g} / \mathrm{dl})$} & 10.32 & 10.68 & 9.28 \\
\hline & $(1.61)$ & $(1.50)$ & $(1.73)$ \\
\hline \multirow[t]{2}{*}{ Anaemic $(\mathrm{Hb}<10 \mathrm{~g} / \mathrm{dl})$} & 0.380 & 0.273 & 0.631 \\
\hline & $(0.485)$ & $(0.447)$ & $(0.483)$ \\
\hline \multicolumn{4}{|c|}{ Panel B: Demographics at Baseline (Children Sample) } \\
\hline \multirow[t]{2}{*}{ Mother has no education } & 0.313 & 0.170 & 0.578 \\
\hline & $(0.463)$ & $(0.377)$ & $(0.494)$ \\
\hline \multirow[t]{2}{*}{ Christian religion } & 0.874 & 0.933 & 0.690 \\
\hline & $(0.332)$ & $(0.250)$ & $(0.463)$ \\
\hline \multirow[t]{2}{*}{ Dangme ethnicity } & 0.642 & 0.648 & 0.032 \\
\hline & $(0.479)$ & $(0.479)$ & $(0.177)$ \\
\hline \multirow[t]{2}{*}{ Radio } & 0.754 & 0.818 & 0.723 \\
\hline & $(0.431)$ & $(0.387)$ & $(0.659)$ \\
\hline \multirow[t]{2}{*}{ Television } & 0.319 & 0.491 & 0.226 \\
\hline & $(0.466)$ & $(0.501)$ & $(0.819)$ \\
\hline \multirow[t]{2}{*}{ Refrigerator } & 0.160 & 0.364 & 0.120 \\
\hline & $(0.367)$ & $(0.483)$ & $(0.586)$ \\
\hline \multirow[t]{2}{*}{ Bicycle } & 0.268 & 0.370 & 0.448 \\
\hline & $(0.443)$ & $(0.484)$ & $(0.733)$ \\
\hline \multirow[t]{2}{*}{ Children in household } & 1.44 & 1.515 & 1.954 \\
\hline & $(0.64)$ & $(0.650)$ & $(1.025)$ \\
\hline \multirow[t]{2}{*}{ Male child } & 0.50 & 0.53 & 0.515 \\
\hline & $(0.50)$ & $(0.501)$ & $(0.500)$ \\
\hline \multirow[t]{2}{*}{ Distance from health centre $5 \geq 10 \mathrm{~km}$} & 0.20 & 0.127 & $\mathrm{n} / \mathrm{a}$ \\
\hline & $(0.40)$ & $(0.334)$ & \\
\hline \multirow[t]{2}{*}{ Distance from health centre $>10 \mathrm{~km}$} & 0.16 & 0.000 & $\mathrm{n} / \mathrm{a}$ \\
\hline & $(0.37)$ & $(0.000)$ & \\
\hline \multirow[t]{2}{*}{ Age of child (months) } & 32.3 & 31.7 & 31.8 \\
\hline & $(15.7)$ & (15.4) & $(15.7)$ \\
\hline Number of children & 2,525 & 165 & 1,473 \\
\hline
\end{tabular}

Notes: Descriptive statistics from the Ghana DHS 2008 uses the sample of children under five years old in rural areas for which there are data on haemoglobin concentration. 
TABLE A2

EFFECT ON USE OF OTHER TYPES OF HEALTH PROVIDER

\begin{tabular}{|c|c|c|c|c|}
\hline & \multirow{2}{*}{$\begin{array}{c}\text { Full sample of } \\
\text { children }\end{array}$} & \multicolumn{2}{|c|}{ By anaemia status at baseline } & \multirow{3}{*}{$\begin{array}{c}\text { Test } \\
\text { (ill=healthy) } \\
\begin{array}{c}\text {-value } \\
(4)\end{array}\end{array}$} \\
\hline & & Anaemic & Not anaemic & \\
\hline & $(1)$ & $(2)$ & (3) & \\
\hline \multicolumn{5}{|c|}{ Panel A: Use of health care at extensive margin } \\
\hline \multirow[t]{3}{*}{ Any clinic visit } & 0.036 & 0.087 & 0.002 & 0.035 \\
\hline & $(0.021)^{*}$ & $(0.031) * * *$ & $(0.026)$ & \\
\hline & {$[0.629]$} & {$[0.614]$} & [0.639] & \\
\hline \multirow[t]{3}{*}{ Any hospital visit } & -0.007 & 0.017 & -0.021 & 0.209 \\
\hline & $(0.015)$ & $(0.025)$ & $(0.019)$ & \\
\hline & [0.153] & {$[0.147]$} & {$[0.157]$} & \\
\hline \multirow[t]{3}{*}{ Any pharmacy visit } & -0.029 & -0.055 & -0.013 & 0.326 \\
\hline & $(0.021)$ & $(0.034)$ & $(0.027)$ & \\
\hline & {$[0.665]$} & {$[0.680]$} & {$[0.655]$} & \\
\hline \multirow[t]{3}{*}{ Any traditional healer visit } & 0.013 & -0.002 & 0.026 & 0.087 \\
\hline & $(0.008)$ & $(0.011)$ & $(0.012)^{* *}$ & \\
\hline & [0.035] & {$[0.045]$} & {$[0.029]$} & \\
\hline \multicolumn{5}{|c|}{ Panel B: Number of health care visits } \\
\hline \multirow[t]{3}{*}{ Clinic visits per year } & 0.286 & 0.525 & 0.136 & 0.113 \\
\hline & $(0.127)^{* *}$ & $(0.203) * * *$ & $(0.153)$ & \\
\hline & {$[2.516]$} & {$[2.448]$} & {$[2.560]$} & \\
\hline \multirow[t]{3}{*}{ Hospital visits per year } & -0.029 & 0.070 & -0.090 & 0.145 \\
\hline & $(0.055)$ & $(0.091)$ & $(0.066)$ & \\
\hline & [0.471] & {$[0.456]$} & {$[0.481]$} & \\
\hline \multirow[t]{3}{*}{ Pharmacy visits per year } & -0.302 & -0.573 & -0.134 & 0.093 \\
\hline & $(0.134)^{* *}$ & $(0.207) * * *$ & $(0.169)$ & \\
\hline & {$[2.971]$} & [3.096] & [2.890] & \\
\hline \multirow[t]{3}{*}{ Traditional healer visits per year } & 0.011 & -0.029 & 0.037 & 0.199 \\
\hline & $(0.029)$ & $(0.044)$ & $(0.034)$ & \\
\hline & [0.110] & [0.132] & [0.096] & \\
\hline
\end{tabular}

Notes: $* * *$ denotes significance at $1 \%, * *$ at $5 \%$, and $*$ at $10 \%$ level. Standard errors, corrected for clustering at the household level, are reported in parentheses. . The mean of the dependent variable in the control group is reported in square brackets. Regressions in Panel A use probit estimation with marginal coefficient estimates reported. Regressions in Panel B are estimated by OLS. Demographics include controls for mother's education, number of children in household, age of the child, household wealth and dummies for male child, distance from the nearest health centre, Christian religion and Dangme ethnicity. Anaemia is defined as having a haemoglobin concentration of less than $10 \mathrm{~d} / \mathrm{gl}$. 
TABLE A3

RobustNesS TO EXCLUSION OF CHILDREN WITH SEVERE ANAEMIA AT BASELINE

\begin{tabular}{|c|c|c|c|c|}
\hline & \multirow{2}{*}{$\begin{array}{l}\text { Full sample of } \\
\text { children }\end{array}$} & \multicolumn{2}{|c|}{ By anaemia status at baseline } & \multirow{2}{*}{$\begin{array}{c}\text { Test } \\
\text { (ill=healthy) } \\
p \text {-value }\end{array}$} \\
\hline & & $\begin{array}{c}\text { Moderately } \\
\text { anaemic }\end{array}$ & & \\
\hline & (1) & $(2)$ & (3) & (4) \\
\hline \multicolumn{5}{|c|}{ Panel A: Use of health care } \\
\hline \multirow[t]{3}{*}{ Clinic visits per year } & 0.286 & 0.568 & 0.141 & 0.110 \\
\hline & $(0.127)^{* *}$ & $(0.230)^{* *}$ & $(0.153)$ & \\
\hline & [2.516] & [2.492] & {$[2.560]$} & \\
\hline \multirow[t]{3}{*}{ Any clinic visit (\%) } & 0.036 & 0.092 & 0.002 & 0.035 \\
\hline & $(0.021)^{*}$ & $(0.034) * * *$ & $(0.026)$ & \\
\hline & {$[0.629]$} & [0.619] & [0.639] & \\
\hline \multicolumn{5}{|c|}{ Panel B: Anaemia } \\
\hline \multirow[t]{3}{*}{ Haemoglobin level } & 0.047 & 0.169 & -0.062 & 0.075 \\
\hline & $(0.063)$ & $(0.107)$ & $(0.076)$ & \\
\hline & [11.015] & [10.559] & [11.399] & \\
\hline \multirow[t]{3}{*}{ Anaemia (\%) } & -0.014 & -0.032 & 0.013 & 0.187 \\
\hline & $(0.018)$ & $(0.025)$ & $(0.023)$ & \\
\hline & {$[0.238]$} & {$[0.339]$} & {$[0.151]$} & \\
\hline
\end{tabular}

Notes: $* * *$ denotes significance at $1 \%, * *$ at $5 \%$, and $*$ at $10 \%$ level. Standard errors, corrected for clustering at the household level, are reported in parentheses. . The mean of the dependent variable in the control group is reported in square brackets. Regressions in Panel A use probit estimation with marginal coefficient estimates reported. Regressions in Panel B are estimated by OLS. Demographics include controls for mother's education, number of children in household, age of the child, household wealth and dummies for male child, distance from the nearest health centre, Christian religion and Dangme ethnicity. Moderate anaemia is defined as having a haemoglobin concentration of less than $10 \mathrm{~d} / \mathrm{gl}$ and greater or equal to $8 \mathrm{~d} / \mathrm{gl}$. 
TABLE A4

Using Alternative Measures of Health to Define SubGroups

\begin{tabular}{|c|c|c|c|c|}
\hline & \multirow{3}{*}{$\begin{array}{c}\text { Full sample of } \\
\text { children } \\
\text { (1) }\end{array}$} & \multicolumn{2}{|c|}{ By health status at baseline } & \multirow{3}{*}{$\begin{array}{c}\text { Test } \\
\text { (ill=healthy) } \\
p \text {-value } \\
(4)\end{array}$} \\
\hline & & Ill & Healthy & \\
\hline & & $(2)$ & (3) & \\
\hline \multicolumn{5}{|c|}{ Panel A: Health defined according to parasitaemia } \\
\hline \multirow[t]{3}{*}{ Any clinic visit (\%) } & 0.036 & 0.039 & 0.037 & 0.963 \\
\hline & $(0.021)^{*}$ & $(0.038)$ & $(0.026)$ & \\
\hline & [0.629] & {$[0.596]$} & [0.644] & \\
\hline \multirow[t]{3}{*}{ Clinic visits per year } & 0.286 & 0.264 & 0.287 & 0.935 \\
\hline & $(0.127)^{* *}$ & $(0.237)$ & $(0.154)^{*}$ & \\
\hline & {$[2.516]$} & {$[2.348]$} & [2.587] & \\
\hline \multirow[t]{3}{*}{ Parasitaemia (\%) } & 0.029 & 0.014 & 0.003 & 0.769 \\
\hline & $(0.017)^{*}$ & $(0.031)$ & $(0.021)$ & \\
\hline & [0.159] & [0.241] & [0.139] & \\
\hline \multirow[t]{3}{*}{ Parasitaemia } & -192.845 & -18.216 & -314.811 & 0.700 \\
\hline & $(232.056)$ & $(720.388)$ & $(223.704)$ & \\
\hline & [700.865] & [1006.414] & {$[654.751]$} & \\
\hline \multicolumn{5}{|c|}{ Panel B: Health defined according to underweight } \\
\hline \multirow[t]{3}{*}{ Any clinic visit (\%) } & 0.036 & 0.032 & 0.036 & 0.949 \\
\hline & $(0.021)^{*}$ & $(0.051)$ & $(0.022)$ & \\
\hline & [0.629] & {$[0.613]$} & {$[0.632]$} & \\
\hline \multirow[t]{3}{*}{ Clinic visits per year } & 0.286 & 0.596 & 0.229 & 0.288 \\
\hline & $(0.127)^{* *}$ & $(0.328)^{*}$ & $(0.133)^{*}$ & \\
\hline & {$[2.516]$} & [2.387] & [2.542] & \\
\hline \multirow[t]{3}{*}{ Underweight (\%) } & -0.002 & -0.015 & 0.010 & 0.434 \\
\hline & $(0.016)$ & $(0.026)$ & $(0.017)$ & \\
\hline & [0.157] & [0.559] & [0.082] & \\
\hline \multirow[t]{3}{*}{ Height for age } & 0.006 & 0.078 & -0.018 & 0.355 \\
\hline & $(0.045)$ & $(0.093)$ & $(0.045)$ & \\
\hline & {$[-0.975]$} & {$[-2.019]$} & {$[-0.783]$} & \\
\hline
\end{tabular}

Notes: $* * *$ denotes significance at $1 \%, * *$ at $5 \%$, and $*$ at $10 \%$ level. Standard errors, corrected for clustering at the household level, are reported in parentheses. . The mean of the dependent variable in the control group is reported in square brackets. Regressions in Panel A use probit estimation with marginal coefficient estimates reported. Regressions in Panel B are estimated by OLS. Demographics include controls for mother's education, number of children in household, age of the child, household wealth and dummies for male child, distance from the nearest health centre, Christian religion and Dangme ethnicity. 